\title{
Analisa Emisi Konduksi Pada Terminal Utama Lampu Hemat Energi
}

\author{
Analysis of Mains Terminal Disturbance Voltage \\ on Energy Saving Lamp
}

\author{
Agung Yanuar Wirapraja \\ Kementerian Perindustrian \\ Balai Riset dan Standardisasi Industri Surabaya \\ Surabaya, Indonesia \\ agungyanuar1945@gmail.com
}

\author{
Ika Prawesty Wulandari \\ Kementerian Perindustrian \\ Balai Riset dan Standardisasi Industri Surabaya \\ Surabaya, Indonesia \\ wulanluvspink@gmail.com
}

\begin{abstract}
Abstrak - Lampu hemat energi (LHE) tidak dapat dipisahkan dari kebutuhan masyarakat saat ini. Lampu hemat energi mempunyai beberapa kelebihan yaitu cahaya yang terang dan konsumsi energi yang rendah. Lampu hemat energi juga memiliki dampak negatif, salah satunya adalah medan magnet yang dihasilkan oleh komponen pasif yang terdapat pada ballast elektronik. Penelitian ini secara khusus menganalisa emisi konduksi yang dihasilkan oleh lampu hemat energi. Penelitian ini menggunakan dua kelompok lampu hemat energi yaitu LHE dengan harga $\leq$ Rp10.000,- dan $>$ Rp10.000,-. Tujuan yang ingin dicapai pada penelitian ini adalah mengetahui emisi konduksi lampu hemat energi yang beredar di Indonesia berdasarkan harganya. Metoda pengujian mengacu pada CISPR 15 yaitu mains terminal disturbance voltage. Pada LHE dengan harga $\leq$ Rp10.000, semua lampu memiliki nilai quasipeak yang melebihi batas limit yang digunakan. $64 \%$ sampel yang diuji, memiliki nilaiquasipeakyang melebihi batas limit yang ada pada CISPR 15.
\end{abstract}

Kata Kunci: LHE, emisi konduksi, CISPR 15, Quasi Peak

\footnotetext{
Abstract-Energy saving lamp (LHE) can not be separated from the needs of today's society. Energy-saving lamps have some advantages such as, bright light and consuming very less energy. Energy saving lamps also have negative effects, one of them is the magnetic field generated by the passive components in the electronic ballast. This study analyzes specifically the conducted emissions generated by energy saving lamps. This study used two groups of energy saving lamps : energy saving lamps at a price $\leq$ 10,000,- IDR and at a price above 10,000,;IDR.. The aim of this research is to determine conducted emission of energy saving lamp in Indonesia market based on the price. The test methods refer to CISPR 15 is mains terminal disturbance voltage. For energy saving lamp at a price $\leq 10,000$ IDR, all the lights have quasipeak value that exceeds the limit used. $64 \%$ of samples tested, have a value that exceeds the limit quasipeak exist in CISPR 15.
}

Keyword : energy saving lamp, conducted emission, CISPR 15, Quasi Peak

\section{PENDAHULUAN}

Lampu adalah alat yang berfungsi untuk memancarkan cahaya. Penggunaan Lampu Hemat Energi (LHE) semakin meningkat dari tahun ke tahun, munculnya lampu LED tidak membuat penggunaan lampu LHE menurun. Berdasarkan data Ketua Umum Asosiasi Perlampuan Indonesia (Aperlindo) penggunaan lampu LHE tahun 2014 mencapai 340 juta unit atau naik dari tahun 2013yang hanya 320 juta unit. Lampu hemat energi banyak digunakan di rumah, toko, rumah sakit dan sebagainya.[1] Lampu hemat energi (LHE) adalah salah satu bentuk pengembangan dari lampu fluorescent. Lampu hemat energi atau yang lebih dikenal sebagai Compact Fluorescent lamp (CFL), lampu penerangan jenis lampu merkuri tekanan rendah yang bekerja berdasarkan lucutan elektron di dalam tabung.[2],[3] Prinsip kerja dari lampu CFL ini sama dengan lampu TL, namun keduanya mempunyai perbedaan yaitu pada peralatan pembatas arus (ballast), di mana lampu TL menggunakan ballast dari induktor yang dihubungkan seri dengan salah satu elektrodanya, sedangkan lampu CFL menggunakan peralatan saklar elektronik sebagai pembatas arusnya (ballast elektronik).[4],[5],[3],[6] Dibandingkan ballast magnetik, ballast elektronik dapat menghemat konsumsi energi sebesar $15 \%$ - 20\%.[7],[8],[9] Ballast elektronik adalah konverter elektronika daya yang fungsinya untuk menyuplai discharge lamp.[10],[11],[12] Pada dasarnya, discharge lamp terdiri dari tabung discharge, didalamnya terdapat energi listrik yang diubah menjadi radiasi elektromagnetik. Setelah lampu dinyalakan, tabrakan antara elektron bebas dan atom menghasilkan panas dan suhu yang akan meningkat hingga mencapai kondisi operasi normal.[10] Ballast elektronik banyak digunakan pada lampu hemat 
energi.Lampu hemat energi juga memiliki dampak negatif, antara lain gas merkuri, pancaran sinar ultra violet, polutan listrik, harmonisa dan medan magnet yang dihasilkan oleh komponen pasif yang terdapat pada ballast elektronik.[3],[9]'[13] Medan elektromagnet yang dihasilkan oleh lampu hemat energi adalah medan listrik dan medan magnet. Medan listrik dihasilkan oleh pembentukan muatan listrik karena adanya perbedaan tegangan,sedangkan medan magnet dihasilkan bila ada arus listrik yang mengalir pada ballast elektronik. Peralatan elektronik dapat memancarkan atau menghasilkan gelombang elektromagnetik yang bisa mengakibatkan gangguan kesehatan dan kinerja peralatan listrik di sekitarnya, sehingga diperlukan regulasi batasan maksimum gelombang elektromagnetik yang dipancarkan atau dihasilkan oleh peralatan elektronik. CISPR (Comité International Spécial des Perturbations Radioélectriques) atau dalam Bahasa Inggris disebut International Special Committee on Radio Interference adalah badan standar EMC yang biasa dijadikan acuan oleh dunia internasional.[14],[15] EMC (Electromagnetic Compability) adalah kemampuan perangkat dalam melindungi diri dari lingkungan elektromagnetik serta kemampuan perangkat itu sendiri agar tidak menghasilkan emisi elektromagnetik. Gangguan elektromagnetik atau yang sering disebut EMI (Electromagnetic Inference) merupakan emisi yang diakibatkan oleh sumber-sumber noise melalui radiasi maupun konduksi elektromagnetik.[16] Faktor yang mempengaruhi EMI dapat diklasifikasikan menjadi sifat dari perangkat elektronik yang memancarkan noise, hubungan fisik antara perangkat (jarak), dan kerentanan perangkat yang terkena dampak(electromagnetic shielding).[17] Penelitian ini bertujuan untuk mengetahui karakteristik emisi konduksi (Conducted Emission) yang dihasilkan oleh lampu hemat energi (CFL). Lampu hemat energi yang digunakan dikelompokan berdasarkan harga lampu, ada 2 (dua) kelompok lampu yang akan digunakan. Parameter yang digunakan dalam pengukuran emisi konduksi (Conducted Emission) adalah nilai Quasipeak dan margin Quasipeak antara hasil pengukuran dengan limit yang terdapat pada CISPR 15.[18] Semakin tinggi nilai margin Quasipeak maka semakin rendah emisi konduksi yang dihasilkan oleh sampel uji.

II. BAHAN DAN METODE PENELITIAN

Metode pengujian mengacu pada CISPR 15 Edisi 7.2 2009 - 01:Limits and methods of measurementof radio disturbance characteristics of electrical lighting and similiar equipment. Pengujian yang dilakukan adalah Tegangan gangguan terminal utama (mains terminal disturbance voltage), sesuai padaCISPR 15.[18] Pengukuran mains terminal disturbance voltage dilakukan pada frekuensi $9 \mathrm{kHz}$ sampai dengan 30 MHz. Dalam menganalisa emisi konduksi (Conducted Emision) yang ditimbulkan oleh sampel maka digunakan metode sesuai dengan CISPR 15 (Metode Pengukuran Gangguan Konduksi Pada Terminal Utama). Sampel akan dianggap gagal apabila ada nilai quasipeak yang melebihi nilai limitnya. Nilai limit quasipeak dan limit average sesuai dengan CISPR 15 untuk produk lampu, seperti pada Tabel 1. [18]

TABEL 1. LIMIT MAINS TERMINAL DISTURBANCE VOLTAGE

\begin{tabular}{|c|c|c|}
\hline \multirow[t]{2}{*}{ Frequency range } & \multicolumn{2}{|c|}{$\begin{array}{l}\text { Limits } \\
\mathrm{dB}(\mu \mathrm{V})\end{array}$} \\
\hline & Quasipeak & Average \\
\hline $9 \mathrm{kHz}$ to $50 \mathrm{kHz}$ & 110 & - \\
\hline $50 \mathrm{kHz}$ to $150 \mathrm{kHz}$ & 90 to $80^{b}$ & - \\
\hline $150 \mathrm{kHz}$ to $0,5 \mathrm{MHz}$ & 66 to $56^{\mathrm{b}}$ & 56 to $46^{b}$ \\
\hline $150 \mathrm{kHz}$ to $5,0 \mathrm{MHz}$ & $56^{\mathrm{c}}$ & $46^{\mathrm{c}}$ \\
\hline $5,0 \mathrm{MHz}$ to $30 \mathrm{MHz}$ & 60 & 50 \\
\hline
\end{tabular}

Sampel uji yang digunakan adalah lampu hemat energi (LHE) dengan tipe glasstube 2U. Penelitian ini menggunakan sampel yang beredar dan dijual dipasaran, jumlah sampel yang digunakan adalah 14 buah lampu LHE yang berbeda merk. Sampel dibagi menjadi 2 (dua) kelompok, berdasarkan harga beli dipasar. Kelompok 1 (satu) adalah lampu LHEdengan harga $\leq$ Rp.10.000 dan kelompok 2 (dua) adalah lampu LHE dengan harga > Rp.10.000. Spesifikasi sampel yang digunakan dapat dilihat pada Tabel 2. 
TABEL 2. SPESIFIKASI SAMPEL LAMPU LHE

\begin{tabular}{|c|c|c|c|c|}
\hline \multirow{2}{*}{ Kelompok } & Sampel & $\begin{array}{c}\text { Daya } \\
\text { (Watt) }\end{array}$ & $\begin{array}{c}\text { Tegangan } \\
\text { (Volt) }\end{array}$ & $\begin{array}{c}\text { Frekuensi } \\
\text { (Hz) }\end{array}$ \\
\hline \multirow{4}{*}{ Kelompok 1 } & $\mathrm{A}_{1}$ & 5 & $220-240$ & $50 / 60$ \\
\cline { 2 - 5 } & $\mathrm{A}_{2}$ & 5,8 & 220 & $50-60$ \\
\cline { 2 - 5 } & $\mathrm{A}_{3}$ & 11 & $220-240$ & $50 / 60$ \\
\cline { 2 - 5 } & $\mathrm{A}_{4}$ & 18 & $170-250$ & $50-60$ \\
\cline { 2 - 5 } & $\mathrm{A}_{5}$ & 9 & $170-250$ & 50 \\
\cline { 2 - 5 } & $\mathrm{A}_{6}$ & 5 & 220 & 50 \\
\cline { 2 - 5 } & $\mathrm{A}_{7}$ & 10 & $220-240$ & $50 / 60$ \\
\hline & $\mathrm{B}_{1}$ & 8 & $200-240$ & $50-60$ \\
\cline { 2 - 5 } & $\mathrm{B}_{2}$ & 8 & $220-240$ & $50-60$ \\
\cline { 2 - 5 } & $\mathrm{B}_{3}$ & 11 & $220-240$ & 50 \\
\cline { 2 - 5 } & $\mathrm{B}_{4}$ & 15 & $220-240$ & $50-60$ \\
\cline { 2 - 5 } & $\mathrm{B}_{5}$ & 15 & $220-240$ & $50-60$ \\
\cline { 2 - 5 } & $\mathrm{B}_{6}$ & 8 & $170-250$ & 50 \\
\cline { 2 - 5 } & $\mathrm{B}_{7}$ & 14 & $170-250$ & $50-60$ \\
\hline
\end{tabular}

Sesuai standar yang dipakai, pengujian ini menggunakan ruangan yang dilengkapi dengan ground plane vertikal dan horizontal yang memiliki ukuran $2 \times 2 \mathrm{~m}$. Selain itu pengujian juga menggunakan meja non metal dengan tinggi $40 \mathrm{~cm}$. Peralatan pengukuran yang digunakan adalah LISN (Line Impedance Stabilization Network), Conical metal housing dan ESU26 EMI Test Receiver. Letakan LISN pada ground plane dengan jarak $40 \mathrm{~cm}$ dari vertikal ground plane dan ground dari LISN dihubungkan (Short) dengan horizontal ground plane. Tempatkan sampel diatas meja dengan jarak $80 \mathrm{~cm}$ dari LISN. Ketinggian kabel LISN maupun kabel EUT yang dipersyaratkan adalah $3 \pm 1 \mathrm{~cm}$ dari ground plane.[18]Untuk rangkaian pengujian dapat dilihat pada gambar 1 . Pengambilan data dilakukan pada ruangan tanpa gerakan udara (draught-proof) dengan kelembaban maksimum $65 \%$. Pengukuran dilakukan pada tegangan jala-jala PLN sebesar 220 V. Sampel akan dinyalakan selama 5 menit sebelum dilakukan pengukuran. Pengambilan data dari setiap sampel uji adalah 1 (satu) kali dalam setiap pengujiannya. Hasil emisi konduksi yang didapat dari EMI Test Receiver diproses dan dapat diamati melalui software EMC32 buatan Rohde Schwarz. Pada setiap pengujiannya akan diambil 10 titik quasipeak tertinggi untuk dianalisa. Hasil pengukuran berupa margin yang merupakan selisih nilai antara batas limit yang terdapat pada CISPR 15 dengan nilai qusipeak hasil pengukuran. Seluruh penelitian dilakukan di Laboraturium EMC Baristand Industri Surabaya, dengan menggunakan alat ukur yang telah terkalibrasi dengan baik.

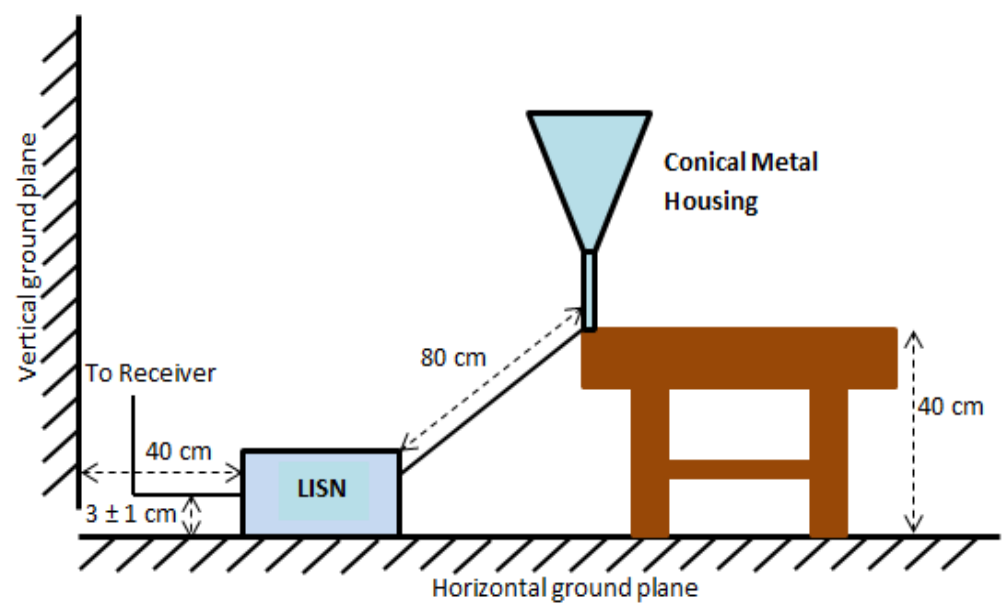

Gambar 1. Rangkaian pengujian conducted emisionmains terminal disturbance voltage 


\section{PEMBAHASAN}

Hasil pengambilan data pengukuran tegangan gangguan terminal utama (mains terminal disturbance voltage) yang dihasilkan oleh lampu hemat energi dilakukan terhadap beberapa merk lampu yang beredar di Indonesia, pengukuran dilakukan dalam kondisi suhu ruang yang dikontrol. Adapun variabel atau besaran yang diukur meliputi frekuensi quasipeak, nilai quasipeak dan margin quasipeak. Hasil pengukuran pada LHE kelompok 1 diperlihatkan pada tabel 3, 4 dan 5, Sedangkan hasil pengukuran LHE kelompok 2 diperlihatkan pada tabel 6, 7 dan 8 berikut ini :

TABEL 3. HASIL PENGUKURAN EMISI KONDUKSI (MAINS TERMINAL) SAMPEL A1, A2 DAN A3

\begin{tabular}{|c|c|c|c|c|c|c|c|c|c|c|c|}
\hline \multicolumn{4}{|c|}{$\mathbf{A}_{1}$} & \multicolumn{4}{|c|}{$\mathbf{\mathbf { A } _ { 2 }}$} & \multicolumn{4}{|c|}{$\mathbf{A}_{3}$} \\
\hline Frekuensi & Limit & Quasipeak & Margin & Frekuensi & Limit & Quasipeak & Margin & Frekuensi & Limit & Quasipeak & Margin \\
\hline (MHz) & $(\mathrm{dB} \mu \mathrm{V})$ & $(\mathrm{dB} \mu \mathrm{V})$ & $(\mathrm{dB})$ & (MHz) & $(\mathrm{dB} \mu \mathrm{V})$ & $(\mathrm{dB} \mu \mathrm{V})$ & $(\mathbf{d B})$ & (MHz) & $(\mathrm{dB} \mu \mathrm{V})$ & $(d B \mu V)$ & $(\mathbf{d B})$ \\
\hline 0,152250 & 655,88 & 85,63 & $-19,75$ & 0,156750 & 65,63 & 88,11 & $-22,48$ & 0,155250 & 65,88 & 92,58 & $-31,55$ \\
\hline 0,183750 & 64,31 & 84,91 & $-20,60$ & 0,219750 & 62,83 & 85,40 & $-22,57$ & 0,192750 & 63,92 & 95,47 & $-31,55$ \\
\hline 0,244500 & 61,94 & 82,02 & $-20,08$ & 0,282750 & 60,73 & 81,27 & $-20,54$ & 0,269250 & 61,14 & 90,62 & $-29,48$ \\
\hline 0,276000 & 60,94 & 80,01 & $-19,07$ & 0,314250 & 59,86 & 77,84 & $-17,98$ & 0,307500 & 60,04 & 86,44 & $-26,40$ \\
\hline 0,337650 & 59,28 & 78,78 & $-19,50$ & 0,345750 & 59,06 & 75,03 & $-15,97$ & 0,384000 & 58,19 & 87,11 & $-28,92$ \\
\hline 0,370500 & 58,49 & 77,14 & $-18,65$ & 0,377250 & 58,34 & 78,50 & $-20,16$ & 0,460500 & 56,68 & 84,79 & $-28,11$ \\
\hline 0,429000 & 57,27 & 76,23 & $-18,96$ & 0,440250 & 57,06 & 76,99 & $-19,93$ & 0,498750 & 56,02 & 79,68 & $-23,66$ \\
\hline 0,462750 & 56,64 & 73,90 & $-17,26$ & 0,503250 & 56,00 & 73,68 & $-17,68$ & 0,575250 & 56,00 & 81,51 & $-25,51$ \\
\hline 0,521250 & 56,00 & 73,51 & $-17,51$ & 0,597750 & 56,00 & 73,16 & $-17,16$ & 0,651750 & 56,00 & 80,26 & $-24,26$ \\
\hline 0,613500 & 56,00 & 71,38 & $-15,38$ & 0,660750 & 56,00 & 71,93 & $-15,93$ & 0,766500 & 56,00 & 75,75 & $-19,75$ \\
\hline Max & & 85,63 & $-15,38$ & Max & & 88,11 & $-15,93$ & Max & & 95,47 & $-19,75$ \\
\hline Min & & 71,38 & $-20,60$ & Min & & 71,93 & $-22,57$ & Min & & 75,75 & $-31,55$ \\
\hline Rata-rata & & 77,00 & $-18,24$ & Rata-rata & & 76,84 & $-18,39$ & Rata-rata & & 83,74 & $-25,74$ \\
\hline
\end{tabular}

TABEL 4. HASIL PENGUKURAN EMISI KONDUKSI (MAINS TERMINALS) SAMPEL $\mathrm{A}_{4}, \mathrm{~A}_{5}$ DAN $\mathrm{A}_{6}$

\begin{tabular}{|c|c|c|c|c|c|c|c|c|c|c|c|}
\hline \multicolumn{4}{|c|}{$\mathbf{A}_{4}$} & \multicolumn{4}{|c|}{$\mathbf{A}_{5}$} & \multicolumn{4}{|c|}{$\mathbf{A}_{6}$} \\
\hline Frekuensi & Limit & Quasipeak & Margin & Frekuensi & Limit & Quasipeak & Margin & Frekuensi & Limit & Quasipeak & Margin \\
\hline (MHz) & $(\mathrm{dB} \mu \mathrm{V})$ & $(\mathrm{dB} \mu \mathrm{V})$ & $(\mathrm{dB})$ & (MHz) & $(\mathrm{dB} \mu \mathrm{V})$ & $(\mathrm{dB} \mu \mathrm{V})$ & $(\mathbf{d B})$ & (MHz) & $(\mathrm{dB} \mu \mathrm{V})$ & $(\mathrm{dB} \mu \mathrm{V})$ & (dB) \\
\hline 0,150000 & 66,00 & 87,21 & $-21,21$ & 0,172500 & 64,84 & 89,83 & $-24,99$ & 0,152250 & 65,88 & 96,09 & $-30,21$ \\
\hline 0,210750 & 63,18 & 80,55 & $-17,37$ & 0,199500 & 63,63 & 92,61 & $-28,98$ & 0,183750 & 64,31 & 88,20 & $-23,89$ \\
\hline 0,240000 & 62,10 & 82,10 & $-20,00$ & 0,228750 & 62,49 & 92,79 & $-30,30$ & 0,215250 & 63,00 & 90,55 & $-27,55$ \\
\hline 0,300750 & 60,22 & 78,63 & $-18,41$ & 0,285000 & 60,67 & 90,69 & $-30,02$ & 0,244500 & 61,94 & 87,73 & $-25,79$ \\
\hline 0,359250 & 58,75 & 71,84 & $-13,09$ & 0,314250 & 59,86 & 86,20 & $-26,34$ & 0,276000 & 60,94 & 81,78 & $-20,84$ \\
\hline 0,390750 & 58,05 & 76,99 & $-18,94$ & 0,370500 & 58,49 & 87,24 & $-28,75$ & 0,305250 & 60,10 & 86,49 & $-26,39$ \\
\hline 0,449250 & 56,89 & 75,09 & $-18,20$ & 0,429000 & 57,27 & 89,96 & $-32,69$ & 0,366000 & 58,59 & 81,74 & $-23,15$ \\
\hline 0,496500 & 56,06 & 75,15 & $-19,09$ & 0,456000 & 56,77 & 80,62 & $-23,85$ & 0,397500 & 57,91 & 82,87 & $-24,96$ \\
\hline 0,541500 & 56,00 & 71,31 & $-15,31$ & 0,514500 & 56,00 & 83,46 & $-27,46$ & 0,485250 & 56,72 & 82,72 & $-26,00$ \\
\hline 0,600000 & 56,00 & 69,83 & $-13,83$ & 0,600000 & 56,00 & 76,88 & $-20,88$ & 0,519000 & 56,00 & 78,71 & $-22,71$ \\
\hline Max & & 87,21 & $-13,09$ & Max & & 92,79 & $-20,88$ & Max & & 96,09 & $-20,84$ \\
\hline Min & & 69,83 & $-21,21$ & Min & & 76,88 & $-32,69$ & Min & & 78,71 & $-30,21$ \\
\hline Rata-rata & & 75,80 & $-17,12$ & Rata-rata & & 85,75 & $\begin{array}{l}-27,39 \\
\end{array}$ & Rata-rata & & 84,74 & $-24,84$ \\
\hline
\end{tabular}

TABEL 5. HASIL PENGUKURAN EMISI KONDUKSI (MAINS TERMINALS) SAMPEL $\mathrm{A}_{7}$

\begin{tabular}{cccc}
\hline \multicolumn{4}{c}{$\mathbf{A}_{\mathbf{7}}$} \\
\hline Frekuensi & Limit & Quasipeak & Margin \\
\hline $\mathbf{( M H z})$ & $\mathbf{( d B} \boldsymbol{\mu} \mathbf{V})$ & $(\mathbf{d B} \boldsymbol{\mu} \mathbf{V})$ & $(\mathbf{d B})$ \\
\hline \hline 0,190500 & 64,01 & 88,99 & $-24,98$ \\
\hline 0,228750 & 62,49 & 87,55 & $-25,06$ \\
\hline 0,305250 & 60,10 & 83,63 & $-23,53$ \\
\hline 0,343500 & 59,12 & 83,12 & $-24,00$ \\
\hline 0,417750 & 57,49 & 77,87 & $-20,38$ \\
\hline 0,456000 & 56,77 & 76,75 & $-19,98$ \\
\hline 0,532500 & 56,00 & 75,20 & $-19,20$ \\
\hline 0,570750 & 56,00 & 74,86 & $-18,86$ \\
\hline 0,647250 & 56,00 & 75,39 & $-19,39$ \\
\hline 0,762000 & 56,00 & 73,69 & $-17,69$ \\
\hline Max & 88,99 & $-17,69$ \\
\hline Min & & 73,69 & $-25,06$ \\
\hline Rata-rata & 78,32 & $-20,58$ \\
\hline \hline
\end{tabular}


Pada hasil pengukuran emisi konduksi (mains terminal disturbance voltage)pada LHE kelompok 1 (harga < 10.000), nilai pengukuran quasipeak pada ketujuh sampel ternyata melebihi nilai limit yang diijinkan pada CISPR 15. LHE pada kelompok 1 tidak memenuhi peryaratan uji emisi konduksi pada pengujian tegangan gangguan terminal utama (mains terminal disturbance voltage) yang ada pada CISPR 15. Emisi konduksi tegangan gangguan terminal utamapada LHE kelompok 1 terdapat pada frekuensi $150-800 \mathrm{kHz}$. Pada sampel LHE $\mathrm{A}_{1}$ nilai pengukuran quasipeak tertinggi adalah
85,63 dB $\mu \mathrm{V}$, lampu $\mathrm{A}_{2}$ adalah $88,11 \mathrm{~dB} \mu \mathrm{V}$, lampu $\mathrm{A}_{3}$ adalah 95,47 dB $\mu \mathrm{V}$, lampu $\mathrm{A}_{4}$ adalah 87,21 $\mathrm{dB} \mu \mathrm{V}$, lampu $\mathrm{A}_{5}$ adalah 92,79 $\mathrm{dB} \mu \mathrm{V}$, lampu $\mathrm{A}_{6}$ adalah $96,09 \mathrm{~dB} \mu \mathrm{V}$ dan lampu $\mathrm{A}_{7}$ adalah $88,99 \mathrm{~dB} \mu \mathrm{V}$. Sedangkan nilai margin antara quasipeak dan limit terendah terdapat pada LHE $\mathrm{A}_{5}$ yaitu sebesar -32,69 $\mathrm{dB} \mu \mathrm{V}$ dan margin tertinggi terdapat pada LHE B4 yaitu $13,09 \mathrm{~dB} \mu \mathrm{V}$. Dari pengukuran emisi konduksi tegangan gangguan terminal utama (mains terminal disturbance voltage) nilai quasipeak tertinggi berada di frekuensi $150-200$ $\mathrm{kHz}$.

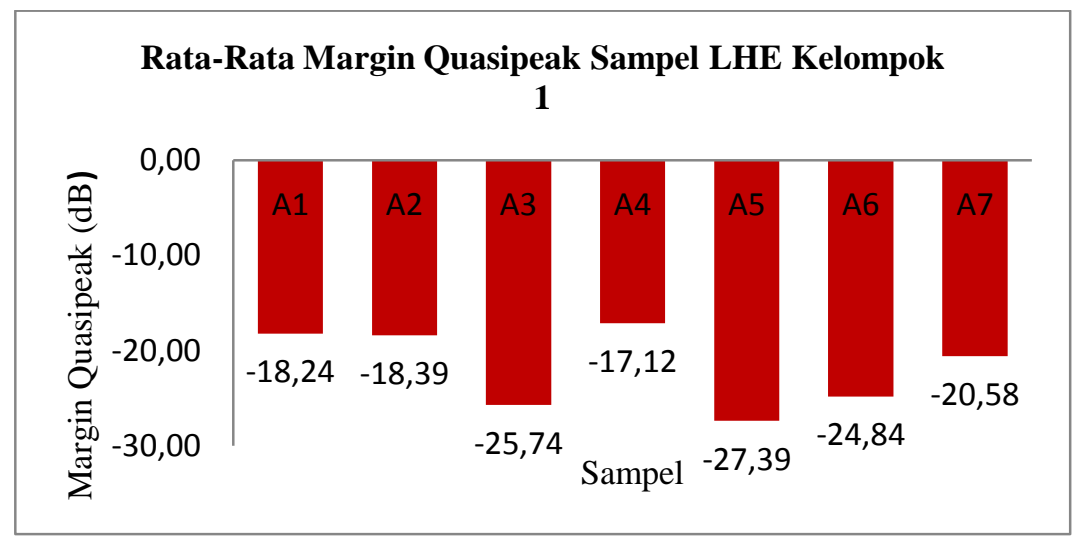

Gambar 2. Margin quasipeak pada sampel LHE kelompok 1

Pada gambar 2, dapat dilihat hasil perbandingan uji emisi konduksi (mains terminal disturbance voltage) pada kelompok 1.Nilai rata-rata margin pada LHE kelompok 1 bernilai minus (-) karena nilai pengukuran quasipeaknya melebihi nilai limit yang digunakan pada CISPR 15. Rata-rata margin quasipeak tertinggi terdapat pada sampel $\mathrm{A}_{4}$ yaitu sebesar $-17,12 \mathrm{~dB} \mu \mathrm{V}$ dan rata-rata margin quasipeak terendah terdapat pada LHE $\mathrm{A}_{5}$ yaitu $-27,39 \mathrm{~dB} \mu \mathrm{V}$.

TABEL 6. HASIL PENGUKURAN EMISI KONDUKSI (MAINS TERMINALS) SAMPEL $\mathrm{B}_{1}, \mathrm{~B}_{2}$ DAN $_{3}$

\begin{tabular}{|c|c|c|c|c|c|c|c|c|c|c|c|}
\hline \multicolumn{4}{|c|}{$\mathbf{B}_{1}$} & \multicolumn{4}{|c|}{$\mathbf{B}_{2}$} & \multicolumn{4}{|c|}{$\mathbf{B}_{3}$} \\
\hline Frekuensi & Limit & Quasipeak & Margin & Frekuensi & Limit & Quasipeak & Margin & Frekuensi & Limit & Quasipeak & Margin \\
\hline (MHz) & $(\mathrm{dB} \mu \mathrm{V})$ & $(\mathbf{d B} \boldsymbol{\mu} \mathbf{V})$ & $(\mathrm{dB})$ & (MHz) & $(\mathrm{dB} \mu \mathrm{V})$ & $(\mathbf{d B} \boldsymbol{\mu} \mathrm{V})$ & $(\mathrm{dB})$ & (MHz) & $(\mathrm{dB} \mu \mathrm{V})$ & $(\mathrm{dB} \mu \mathrm{V})$ & (dB) \\
\hline 0,097350 & 83,94 & 54,15 & 29,79 & 0,150000 & 66,00 & 93,59 & $-27,59$ & 0,183750 & 64,31 & 85,64 & $-21,33$ \\
\hline 0,150000 & 66,00 & 63,07 & 2,93 & 0,197250 & 63,73 & 88,24 & $-24,51$ & 0,228750 & 62,49 & 88,57 & $-26,08$ \\
\hline 0,206250 & 63,35 & 49,89 & 13,46 & 0,249000 & 61,79 & 90,52 & $-28,73$ & 0,231000 & 62,41 & 87,32 & $-24,91$ \\
\hline 0,242250 & 62,02 & 49,34 & 12,68 & 0,345750 & 59,06 & 85,73 & $-26,67$ & 0,280500 & 60,80 & 78,65 & $-17,85$ \\
\hline 0,291750 & 60,47 & 44,36 & 16,11 & 0,397500 & 57,91 & 82,69 & $-24,78$ & 0,321000 & 59,68 & 81,61 & $-21,93$ \\
\hline 0,390750 & 58,05 & 31,46 & 26,59 & 0,496500 & 56,06 & 81,03 & $-24,97$ & 0,368250 & 58,54 & 79,38 & $-20,84$ \\
\hline 0,438000 & 57,10 & 34,00 & 23,10 & 0,591000 & 56,00 & 77,21 & $-21,21$ & 0,458250 & 56,72 & 77,56 & $-20,84$ \\
\hline 0,487500 & 56,21 & 28,36 & 27,85 & 0,647250 & 56,00 & 76,66 & $-20,66$ & 0,548250 & 56,00 & 72,61 & $-16,61$ \\
\hline 0,584250 & 56,00 & 30,74 & 25,26 & 0,744000 & 56,00 & 75,68 & $-19,68$ & 0,595500 & 56,00 & 74,17 & $-18,17$ \\
\hline 0,681000 & 56,00 & 18,75 & 37,25 & 0,838500 & 56,00 & 72,36 & $-16,36$ & 0,683250 & 56,00 & 72,82 & $-16,82$ \\
\hline Max & & 63,07 & 37,25 & Max & & 93,59 & $-16,36$ & Max & & 88,57 & $\begin{array}{l}-16,61 \\
\end{array}$ \\
\hline Min & & 18,75 & 2,93 & Min & & 72,36 & $-28,73$ & Min & & 72,61 & $-26,08$ \\
\hline Rata-rata & & 36,87 & 22,25 & Rata-rata & & 80,78 & $-22,82$ & Rata-rata & & 78,53 & $-20,07$ \\
\hline
\end{tabular}


TABEL 7. HASIL PENGUKURAN EMISI KONDUKSI (MAINS TERMINALS) SAMPEL $\mathrm{B}_{4}, \mathrm{~B}_{5}$ DAN $_{6}$

\begin{tabular}{|c|c|c|c|c|c|c|c|c|c|c|c|}
\hline \multicolumn{4}{|c|}{$\mathbf{B}_{4}$} & \multicolumn{4}{|c|}{$\mathbf{B}_{5}$} & \multicolumn{4}{|c|}{$\mathbf{B}_{6}$} \\
\hline Frekuensi & Limit & Quasipeak & Margin & Frekuensi & Limit & Quasipeak & Margin & Frekuensi & Limit & Quasipeak & Margin \\
\hline (MHz) & $(\mathrm{dB} \mu \mathrm{V})$ & $(\mathrm{dB} \mu \mathrm{V})$ & (dB) & (MHz) & $(\mathrm{dB} \mu \mathrm{V})$ & $(\mathrm{dB} \mu \mathrm{V})$ & (dB) & (MHz) & $(\mathrm{dB} \mu \mathrm{V})$ & $(\mathrm{dB} \mu \mathrm{V})$ & $(\mathbf{d B})$ \\
\hline 0,312000 & 59,92 & 37,44 & 22,48 & 0,323250 & 59,62 & 48,23 & 11,39 & 0,152250 & 65,88 & 48,45 & 17,43 \\
\hline 0,390750 & 58,05 & 36,58 & 21,47 & 0,402000 & 57,81 & 46,24 & 11,57 & 0,204000 & 63,45 & 45,75 & 17,70 \\
\hline 0,469500 & 56,52 & 37,15 & 19,37 & 0,483000 & 56,29 & 44,81 & 11,48 & 0,305250 & 60,10 & 38,58 & 21,52 \\
\hline 0,519000 & 56,00 & 44,74 & 11,26 & 0,523500 & 56,00 & 42,59 & 13,41 & 0,379500 & 58,29 & 40,39 & 17,90 \\
\hline 0,546000 & 56,00 & 34,40 & 21,60 & 0,564000 & 56,00 & 46,23 & 9,77 & 0,406500 & 57,72 & 33,00 & 24,72 \\
\hline 0,624750 & 56,00 & 37,08 & 18,92 & 0,642750 & 56,00 & 40,58 & 15,42 & 0,458250 & 56,72 & 32,59 & 24,13 \\
\hline 0,701250 & 56,00 & 32,85 & 23,15 & 0,683250 & 56,00 & 38,07 & 17,93 & 0,507750 & 56,00 & 29,13 & 26,87 \\
\hline 0,782250 & 56,00 & 39,57 & 16,43 & 0,723750 & 56,00 & 40,52 & 15,48 & 0,609000 & 56,00 & 29,12 & 26,88 \\
\hline 0,858750 & 56,00 & 40,39 & 15,61 & 0,804750 & 56,00 & 39,65 & 16,35 & 0,712500 & 56,00 & 24,23 & 31,77 \\
\hline 0,937500 & 56,00 & 37,29 & 18,71 & 0,885750 & 56,00 & 40,14 & 15,86 & 0,813750 & 56,00 & 28,26 & 27,74 \\
\hline Max & & 44,74 & 23,15 & Max & & 48,23 & 17,93 & Max & & 48,45 & 31,77 \\
\hline Min & & 32,85 & 11,26 & Min & & 38,07 & 9,77 & Min & & 24,23 & 17,43 \\
\hline Rata-rata & & 38,11 & 17,95 & Rata-rata & & 41,89 & 14,34 & Rata-rata & & 32,80 & 25,07 \\
\hline
\end{tabular}

TABEL 8. HASIL PENGUKURAN EMISI KONDUKSI (MAINS TERMINALS) SAMPEL B 7

\begin{tabular}{cccc}
\hline \multicolumn{4}{c}{$\mathbf{B}_{7}$} \\
\hline Frekuensi & Limit & Quasipeak & Margin \\
\hline$(\mathbf{M H z})$ & $(\mathbf{d B} \boldsymbol{\mu V})$ & $(\mathbf{d B} \boldsymbol{\mu} \mathbf{V})$ & $(\mathbf{d B})$ \\
\hline \hline 0,170250 & 64,95 & 51,05 & 13,90 \\
\hline 0,208250 & 63,26 & 50,28 & 12,98 \\
\hline 0,258000 & 61,50 & 40,38 & 21,12 \\
\hline 0,282750 & 60,73 & 39,16 & 21,57 \\
\hline 0,334500 & 59,34 & 36,10 & 23,24 \\
\hline 0,404250 & 57,77 & 35,13 & 22,64 \\
\hline 0,444750 & 56,97 & 34,75 & 22,22 \\
\hline 0,606750 & 56,00 & 34,53 & 21,47 \\
\hline 1,077000 & 56,00 & 25,56 & 30,44 \\
\hline 1,164750 & 56,00 & 31,61 & 24,39 \\
\hline Max & 51,05 & 30,44 \\
\hline Min & & 25,56 & 12,98 \\
\hline Rata-rata & 35,38 & 23,05 \\
\hline \hline
\end{tabular}

Pada hasil pengukuran emisi konduksi (mains terminal disturbance voltage)pada LHE kelompok 2 (harga < 10.000), dari nilai pengukuran quasipeak pada ketujuh lampu dapat diketahui bahwa ada lima (5) lampu yang memenuhi standart sesuai dengan CISPR 15 dan dua (2) lampu yang tidak memenuhi standart karena margin quasipeaknya melebihi nilai limit yang diijinkan pada CISPR 15. Emisi konduksi tegangan gangguan terminal utama pada LHE kelompok 2 terdapat pada frekuensi $150-1,2 \mathrm{MHz}$. Pada sampel LHE $\mathrm{B}_{1}$ nilai pengukuran quasipeak tertinggi adalah $63,07 \mathrm{~dB} \mu \mathrm{V}$, lampu $\mathrm{B}_{2}$ adalah 93,59 dB $\mu \mathrm{V}$, lampu $\mathrm{B}_{3}$ adalah $88,57 \mathrm{~dB} \mu \mathrm{V}$, lampu $\mathrm{B}_{4}$ adalah 44,74 dB $\mu \mathrm{V}$, lampu $\mathrm{B}_{5}$ adalah $48,23 \mathrm{~dB} \mu \mathrm{V}$, lampu $\mathrm{B}_{6}$ adalah 48,45 $\mathrm{dB} \mu \mathrm{V}$ dan lampu $\mathrm{B}_{7}$ adalah 51,05 $\mathrm{dB} \mu \mathrm{V}$. Sedangkan nilai margin antara quasipeak dan limit terendah terdapat pada LHE $B_{2}$ yaitu sebesar $-28,73 \mathrm{~dB} \mu \mathrm{V}$ dan margin tertinggi terdapat pada LHE $B_{1}$ sebesar $37,25 \mathrm{~dB} \mu \mathrm{V}$. Dari pengukuran emisi konduksi tegangan gangguan terminal utama (mains terminal disturbance voltage) nilai quasipeak tertinggi berada di frekuensi $90-600 \mathrm{kHz}$. 


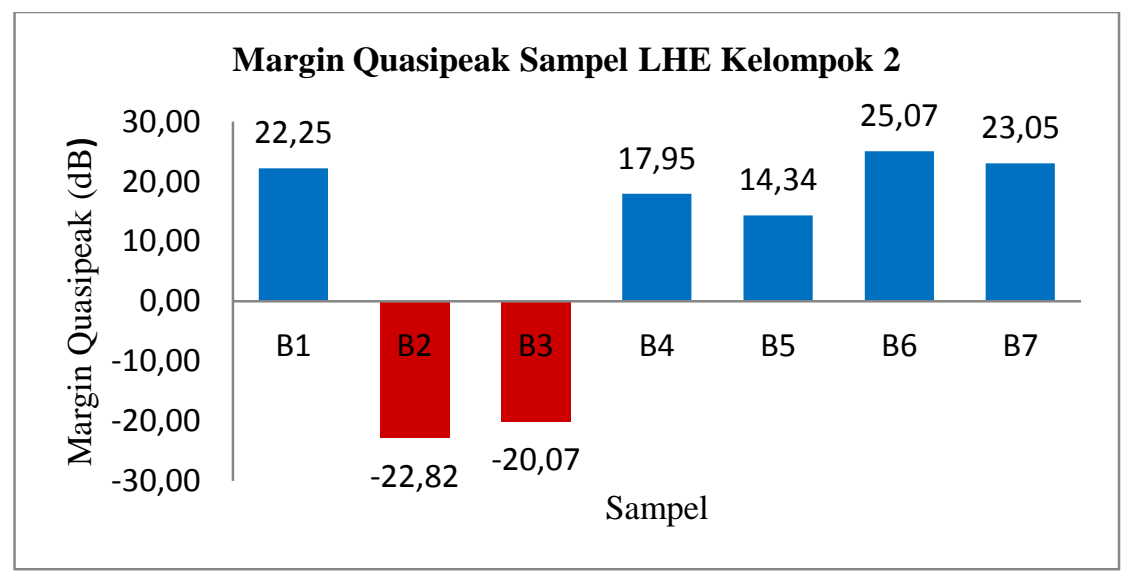

Gambar 3. Margin quasipeak pada sampel LHE kelompok 2

Pada gambar 2, dapat dilihat hasil perbandingan uji emisi konduksi (mains terminal disturbance voltage) pada kelompok 2. Nilai rata-rata margin pada LHE kelompok 2, pada LHE $B_{1}$, $\mathrm{B}_{4}, \mathrm{~B}_{5}, \mathrm{~B}_{6}$ dan $\mathrm{B}_{7}$ margin quasipeaknya bernilai positif (+) sedangkan pada LHE $\mathrm{B}_{2}$ dan $\mathrm{B}_{3}$ margin quasipeaknya bernilai minus (-) karena nilai pengukuran quasipeaknya melebihi nilai limit yang digunakan pada CISPR 15. Rata-rata nilai margin quasipeak tertinggi terdapat pada sampel B6 yaitu sebesar $25,07 \mathrm{~dB} \mu \mathrm{V}$ dan rata-rata margin quasipeak terendah terdapat pada LHE B2 yaitu $-22,82 \mathrm{~dB} \mu \mathrm{V}$.

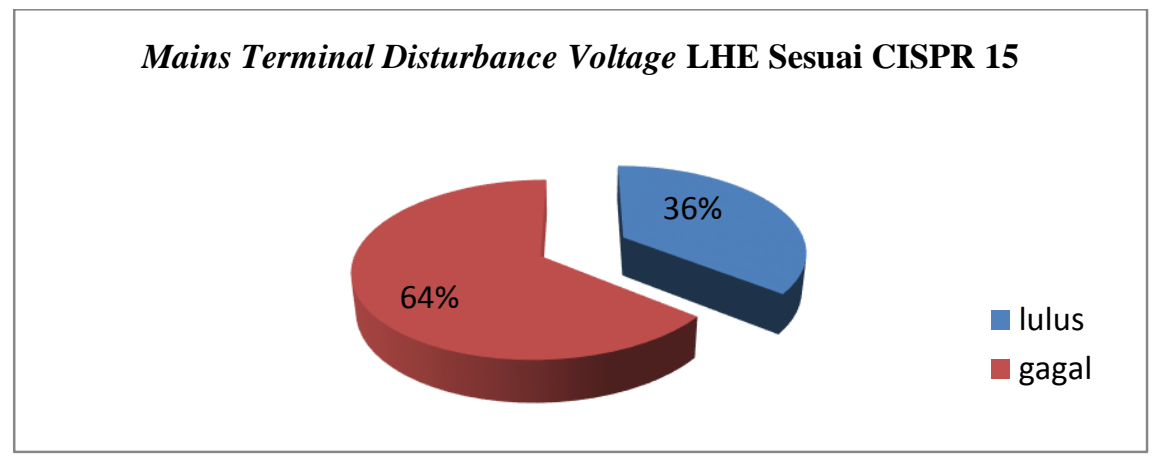

Gambar 4. Hasil uji lampu hemat energi

Dari diagram diatas dapat dilihat $64 \%$ LHE memiliki emisi konduksi tegangan gangguan terminal utama (mains terminal disturbance voltage) yang melebihi batas yang diijinkan pada CISPR 15. Dari keseluruhan LHE yang gagal, tujuh (7) lampu berasal dari kelompok 1 dan dua (2) lampu dari kelompok 2. LHE yang lulus atau memenuhi standart CISPR 15 sebesar 36\% dari keseluruhan LHE yang digunakan dalam pengujian.

\section{KESIMPULAN}

Hasil pengukuran dari dua kelompok LHE, menunjukkan 64\% LHE tidak memenuhi persyaratan pada CISPR 15 sedangkan 36\% sisanya memenuhi persyaratan pada CISPR 15. Pada kelompok 1 (harga $\leq \mathrm{Rp} 10.000,-$ ) semua LHE $(100 \%)$ tidak memenuhi persyaratan uji emisi konduksi:tegangan gangguan terminal utama (mains terminal disturbance voltage). Pada kelompok 2 (harga > Rp 10.000,-) terdapat 5 (lima) LHE yang memenuhi persyaratan dan ada 2 (dua) LHE yang tidak memenuhi persyaratan pada CISPR 15.
Harga lampu hemat energi (LHE) berpengaruh terhadap emisi konduksi yang timbulkan oleh lampu tersebut.

\section{UCAPAN TERIMA KASIH}

Ucapan terima kasih diucapkan kepada Baristand Industri khususnya Laboratorium Elektronika dan Telematika yang menyediakan seluruh fasilitas pengujian EMC, khususnya untuk pengukuran nilai emisi.

\section{DAFTAR PUSTAKA}

[1] C. Uyaisom, "Effect of Jumbo Compact Fluorescent Lamp on the Electrical Energy Saving and Harmonics Noise," Procedia Eng., vol. 8, pp. 149-153, 2011.

[2] R. A. Jabbar, M. Al-Dabbagh, A. Muhammad, R. H. Khawaja, M. Akmal, and M. R. Arif, "Impact of compact fluorescent lamp on power quality," in Proceedings of the Australasian Universities Power Engineering Conference (AUPEC '08), 2008, pp. 1-5.

[3] L. Assaffat, “Analisa pejanan medan magnet pada lampu 
hemat energi," in Prosiding Seminar Nasional Sains \& Teknologi, 2010, pp. 40-44.

[4] A. Razikin, M. Siregar, J. Islami, and Syaifurrahman, "Kajian Pemanfaatan Ballast Elektronik Bekas Pada Lampu TL,” J. ELKHA, vol. 5, no. 1, pp. 10-14, 2013.

[5] R. Rigo-Mariani, R. K. Rayudu, M. S. Witherden, and E. M. Lai, "Power quality indices of Compact Fluorescent Lamps for residential use - A New Zealand study," in TENCON 2010 - 2010 IEEE Region 10 Conference, 2010, pp. 647652.

[6] Supriono and I Nyoman Wahyu Satiawan, "Peningkatan Kinerja Lampu TL (Fluorescent) pada Catu Daya dengan Regulasi Tegangan Buruk," J. Tek. Elektro, vol. 5, no. 2, pp. 59-66, 2005.

[7] H. Y. Wang, A. V. Stankovic, D. Kachmarik, and L. Nerone, "A novel discrete dimming ballast for linear fluorescent lamps," in PESC Record - IEEE Annual Power Electronics Specialists Conference, 2004, vol. 1, pp. 815820.

[8] S. A. Permana, “ANALISIS PENGGUNAAN BALLAST ELEKTRONIK UNTUK PENGHEMATAN ENERGI LISTRIK PADA BEBAN PENERANGAN," TRANSMISI, vol. 2, no. 16, pp. 100-105, 2014.

[9] P. Chiradeja, A. Ngaopitakkul, and C. Jettanasen, "Energy savings analysis and harmonics reduction for the electronic ballast of T5 fluorescent lamp in a building's lighting system," Energy Build., vol. 97, pp. 107-117, 2015.

[10] H. Guldner, K. Lehnert, F. Bohme, and F. Raiser, "Principles of electronic ballasts for fluorescent lamps-an overview," 30th Annu. IEEE Power Electron. Spec. Conf. Rec. (Cat. No.99CH36321), vol. 1, no. c, 1999.

[11] J. M. Alonso, "Electronic ballasts," in Power Electronics Handbook, 2011, pp. 573-599.

[12] K. . Mohamed, H. . Shareef, and A. . Mohamed, "An analysis of harmonic emission from compact fluorescent lamps," Int. Rev. Model. Simulations, vol. 5, no. 1, pp. 278284, 2012.

[13] A. Gil-de-Castro, S. K. Rönnberg, M. H. J. Bollen, and A. Moreno-Muñoz, "Study on harmonic emission of domestic equipment combined with different types of lighting," Int. J. Electr. Power Energy Syst., vol. 55, pp. 116-127, 2014.

[14] S. Braun, "A novel time-domain EMI measurement system for measurement and evaluation of discontinuous disturbance according to CISPR 14 and CISPR 16," IEEE Int. Symp. Electromagn. Compat., pp. 480-483, 2011.

[15] A. Background, "International Special Committee on Radio Interference (CISPR)," CISPR/A/WG1(Ant-Cal/CamellJohnk-Heirman), vol. 1, no. October, pp. 1-6, 2008.

[16] K. Armstrong, "Guide to Testing Conducted Emissions (Based on the Methods in EN 55022 and EN 55011)," In Compliance, pp. 14-27, 2011.

[17] S. E. Lapinsky and A. C. Easty, "Electromagnetic interference in critical care," J.Crit Care, vol. 21, no. 3, pp. 267-270, 2006.

[18] Y. Hiratomo, “照明機器のEMC規格,” in 電気学会産業応用部門大会, 2010, p. I 23-24. 